Maria Clotilde Cella, Giovanna Claudia Mantani, Marta Loli Palazzini, Luisantonia Zuccon, Vita religiosa, carità ed educazione nell'Italia dell'Ottocento. Rosalie Thouret e la fondazione della Provincia modenese delle Suore della Carità (1834-1853)

Macerata, Alfacetica Ed., coll. «Fonti e Documenti », 2007, 614 p.

Michel Ostenc

\title{
OpenEdition
}

Journals

Édition électronique

URL : http://journals.openedition.org/assr/14913

DOI : $10.4000 /$ assr. 14913

ISSN : $1777-5825$

Éditeur

Éditions de l'EHESS

Édition imprimée

Date de publication : 1 juin 2008

Pagination : 191-321

ISBN : 978-2-7132-2190-3

ISSN : 0335-5985

Référence électronique

Michel Ostenc, « Maria Clotilde Cella, Giovanna Claudia Mantani, Marta Loli Palazzini, Luisantonia Zuccon, Vita religiosa, carità ed educazione nell'talia dell'Ottocento. Rosalie Thouret e la fondazione della Provincia modenese delle Suore della Carità (1834-1853) ", Archives de sciences sociales des religions [En ligne], 142 | avril-juin 2008, document 142-13, mis en ligne le 25 novembre 2008, consulté le 21 septembre 2020. URL : http://journals.openedition.org/assr/14913; DOI : https://doi.org/10.4000/ assr. 14913

Ce document a été généré automatiquement le 21 septembre 2020.

(c) Archives de sciences sociales des religions 


\section{Maria Clotilde Cella, Giovanna Claudia Mantani, Marta Loli Palazzini, Luisantonia Zuccon, Vita religiosa, carità ed educazione nell'Italia dell'Ottocento. Rosalie Thouret e la fondazione della Provincia modenese delle Suore della Carità (1834-1853)}

Macerata, Alfacetica Ed., coll. «Fonti e Documenti », 2007, 614 p.

Michel Ostenc

La Révolution française avait interdit au clergé régulier de prononcer des vœux et d'observer la clôture, l'assistance et l'éducation des pauvres restant ses seules vocations reconnues. Les nouvelles fondations religieuses adoptèrent les formes de la congrégation dont les règles canoniques insistaient sur le caractère temporaire des vœux et sur le regroupement de l'institution autour de son noviciat; mais le SaintSiège et la Sacrée Congrégation des Évêques n'accepteront que beaucoup plus tard l'organisation centralisée avec supérieure générale. Ce modèle fut celui des sœurs de la Charité dont la congrégation fut fondée à Besançon au lendemain de la tourmente révolutionnaire, qui durent à l'inlassable activité de Jeanne Antide Thouret leur installation à Naples sous le règne de Murat. Elles durent y surmonter maintes difficultés liées aux survivances de pratiques monastiques d'Ancien Régime dans le royaume des Deux-Siciles; mais leur compétence en matière d'enseignement et d'assistance charitable leur permit de s'imposer dans une vocation qui alliait la tradition paulinienne et les réalités sociales de la Restauration. Dans ces nouvelles congrégations, l'éducation de la jeunesse était considérée comme l'une des formes les plus nobles de la charité et le meilleur moyen de réparer les dommages causés dans les 
âmes par le rationalisme des Lumières ; mais si l'objectif était de restaurer la société chrétienne, ce retour à la foi passait par une éducation capable d'améliorer les conditions sociales.

2 L'ouvrage présenté par Roberto Sani et Anna Ascensi s'attache à l'extension de la congrégation des sœurs de la Charité en Italie centrale à l'instigation de la nièce de la fondatrice, Rosalia Thouret. Cette étude rassemble en annexes une abondante documentation faite de lettres, décrets et actes administratifs puisés par le "Centro di documentazione e ricerca dell'educazione e delle istituzioni scolastiche» de l'université de Macerata dans des dizaines d'archives congréganistes, communales, épiscopales et nationales. La correspondance concerne des personnages impliqués dans le rayonnement des sœurs de la Charité de Modène et les lettres rédigées en français par Rosalie Thouret à la supérieure de la congrégation Geneviève Boucon. On aurait pourtant souhaité que le livre dépassât le stade biographique pour s'immerger davantage dans son contexte historique, et nous nous efforcerons de le faire dans ce compte rendu afin de replacer les faits dans leur environnement politique, social et religieux en Italie centrale.

3 L'arrivée des premières religieuses à Modène répondait aux préoccupations du souverain François IV de Lorraine-Habsbourg, au lendemain des mouvements libéraux qui avaient secoué le duché en 1831. L'enseignement primaire public de la principauté était financé par les communes, le maire s'occupant de la direction didactique et le curé ne disposant que d'un droit d'inspection. Au début de la restauration, un ministère de l'instruction protégeait d'ailleurs les écoles publiques contre la concurrence en exigeant une autorisation d'enseigner pour les maîtres du privé et l'obligation de se conformer aux programmes officiels. La législation scolaire héritée du royaume napoléonien d'Italie ne fut formellement abolie qu'en 1838, même si les signes d'une réaction conservatrice s'étaient manifestés beaucoup plus tôt. Le gouvernement de Modène s'opposa à l'introduction des asiles pour l'enfance créés par le prêtre Ferrante Aporti et il refusa tout enseignement mutuel sous prétexte que les méthodes pédagogiques lancastériennes troublaient celles déjà en place. Il s'agissait de défendre l'enseignement des frères des Écoles chrétiennes, largement majoritaire dans le duché. En outre, le pouvoir princier ne s'attachait guère à la diffusion de l'enseignement primaire dans les campagnes par crainte qu'il ne fût un facteur d'instabilité sociale. Après la crise de 1831, les fonctionnaires locaux envoyèrent au gouvernement des « Relazioni di Buon Governo » qui dénonçaient la précarité de l'enseignement dans les centres ruraux, et François IV édicta un nouveau règlement scolaire instituant une école normale pour former les professeurs du secondaire. Le directeur de cet établissement fut aussi chargé de la réorganisation des écoles primaires communales, mais il s'y employa sans procéder à aucune innovation pédagogique. Les orientations philo-catholiques du souverain se renforcèrent notablement jusqu'à la signature d'un concordat avec le Saint-Siège en 1841, et son dirigisme politique en matière scolaire donna à l'enseignement public une connotation confessionnelle beaucoup plus accusée. L'attention portée à l'éducation des filles se traduisit non seulement par la réouverture de vieux collèges tenus par des religieuses cloîtrées, mais aussi par le recours à de nouvelles congrégations féminines enseignantes. François IV souhaitait enraciner le consensus au régime en exerçant un contrôle direct sur la société, et il entendait y parvenir en multipliant les institutions charitables et scolaires dans le duché. Les sœurs de la Charité furent ainsi affectées à l'hôpital pour femmes de Modène; mais le 
souverain les y introduisit à l'insu de l'évêque Adeodato Caleffi et de son successeur Luigi Reggianini. Elles furent d'emblée l'objet de la méfiance d'un évêché inquiet de leur réputation novatrice et ne purent s'imposer qu'avec la bienveillance d'un administrateur nommé par la Cour. Cesare Galvani était en effet une personnalité de premier plan dans les cercles légitimistes de Modène et sa désignation confirme ce que nous apprend la correspondance de Rosalie Thouret au sujet du soutien du prince aux sœurs de la Charité.

Les religieuses ne limitaient pas leurs activités aux tâches hospitalières et elles visitaient aussi à domicile les malades et les personnes âgées. Elles se dévouèrent corps et âme à la population de Modène atteinte par l'épidémie de choléra de 1836, ce qui leur valut l'extension de leurs attributions à l'assistance hospitalière des hommes. Elles obtinrent la création d'un noviciat qui leur permit d'affirmer leur autonomie par rapport à la communauté de Naples dont elles étaient issues. L'éducation figurait aussi parmi leurs missions; mais ces objectifs d'amélioration des conditions sociales restaient indissociables de la restauration d'une société chrétienne. Les écoles de charité étaient gratuites et conçues pour les filles pauvres qui ne pouvaient fréquenter les écoles primaires. Elles étaient ouvertes tous les jours du matin au soir, avec une seule interruption pour les repas que les élèves pouvaient prendre en rentrant chez elles ou en consommant sur place ce qu'elles avaient apporté. L'assiduité n'était pas obligatoire et il n'y avait pas d'examen terminal. L'année scolaire s'achevait en juin au lieu de septembre, pour laisser aux enfants la possibilité de participer aux travaux des champs, si bien que ces écoles étaient très appréciées des parents. Les religieuses de Modène accomplissaient en outre toutes les missions de leur congrégation au sujet des jeunes filles de bonnes familles. Une école de charité leur fut destinée en 1840 qui comprenait des classes primaires et un pensionnat payants.

5 La congrégation essaima du côté de l'hôpital de Ravenne dès 1838 , à la demande de l'archevêque, le cardinal Carlo Falconieri, et elle sera impliquée dans l'éducation des orphelines de la ville en 1841. Les sœurs de la Charité s'occupèrent à partir de 1851 de l'asile de l'œuvre Tombesi Dall'Ova, premier établissement de ce genre destiné aux enfants en Romagne. Une autre extension de leurs activités charitables les conduisit à l'hôpital de Reggio d'Émilie en 1842, puis à celui de Faenza en 1852. À Bologne, le cardinal Oppizoni avait créé une école gratuite pour les filles pauvres dans chacun des quatre quartiers de la ville. Ces écoles de la Providence, gérées par l'association Pia Unione, étaient tenues par des institutrices laïques qui apprenaient à lire, écrire et compter, ainsi que les rudiments de la doctrine chrétienne. Elles comptaient deux cent cinquante élèves en 1836, mais furent restructurées dans les années 1840. L'association demanda l'aide des sœurs de la Charité de Modène en 1844, mais un conflit ne tarda pas à les opposer au sujet des finalités de l'enseignement et des moyens indispensables pour les satisfaire. Les religieuses avaient un véritable projet éducatif où l'instruction dépassait le stade de l'alphabétisation pour devenir un instrument de promotion sociale. L'association Pia Unione soutenait que deux institutrices suffisaient pour une école de quatre-vingts élèves et suggérait d'utiliser les plus âgées comme tutrices des plus jeunes ; mais les sœurs de la Charité estimaient au contraire que les grandes élèves méritaient plus d'attention et elles demandaient l'agrandissement de l'institution. Le litige fut tranché en leur faveur par le cardinal Oppizoni en 1850. À Ferrare, la Restauration fut également une période novatrice, derrière l'apparente immobilité d'un retour au conservatisme. Les sœurs de la Charité y réorganisèrent les pensionnats destinés aux orphelines et aux jeunes délinquantes qui étaient gérés jusque-là par des 
laïques. La congrégation reçut une reconnaissance de la valeur de ses activités éducatives et charitables lorsqu'on lui confia à Rome, en 1844, la gestion du Conservatorio di San Spirito in Sassia, un établissement hébergeant plus de quatre cents filles abandonnées, et Pesaro la sollicita en 1847 pour s'occuper de son pensionnat pour orphelines. Les religieuses avaient été appelées dès 1845 par l'évêque de cette cité des Marches pour assurer l'éducation des filles, et elles y fondèrent un pensionnat et deux écoles destinées aux pauvres et à la bourgeoisie. Les unes devaient savoir lire, écrire et compter, connaître le catéchisme et pratiquer les travaux domestiques; les autres apprenaient l'orthographe, la grammaire et l'arithmétique, l'histoire, la géographie, la langue française et l'art déclamatoire, la littérature et l'instruction religieuse.

6 Le succès des sœurs de la Charité de Modène valut à Rosalie Thouret d'être nommée à Verceil à la tête d'une province piémontaise qui comptait cinquante-quatre communautés et un noviciat. Les révolutions de 1848 eurent des conséquences néfastes mais momentanées pour la congrégation. Elle fut chassée de Rome par la république de Mazzini et ses établissements d'Émilie et de Romagne furent malmenés. Par contre, le gouvernement provisoire de Modène se montra plus respectueux des institutions ecclésiastiques et des communautés religieuses. La tourmente révolutionnaire fut sans lendemain et les sœurs de la Charité reprirent partout leurs activités antérieures. Leur exemple illustre parfaitement le souci des nouvelles congrégations d'utiliser l'instruction non seulement pour une reconquête religieuse, mais aussi à des fins sociales. Cette adaptation à l'évolution de la société engendrait un esprit d'ouverture dans l'éducation qui s'éloignait en partie du modèle traditionnel des "petites écoles " de l'Ancien Régime et contribuait largement à l'expansion de la congrégation. On aimerait toutefois en savoir davantage sur la pédagogie pratiquée dans les écoles de charité. Cette réserve n'enlève rien aux mérites du livre présenté par R. Sani et A. Ascensi qui ouvre la voie à des approfondissements ultérieurs. 